\title{
Rainy-Season Duration Estimated from OLR versus Rain Gauge Data and the 2001 Drought in Southeast Brazil
}

\author{
Sergio H. Franchito and V. Brahmananda Rao \\ Centro de Previsão de Tempo e Estudos Climáticos, Instituto Nacional de Pesquisas Espaciais, São José dos Campos, Brazil \\ PAULO R. B. BARBIERI \\ Fundação Cearense de Meteorologia (FUNCEME), Fortaleza, Brazil \\ Clovis M. E. SAnto \\ Centro de Previsão de Tempo e Estudos Climáticos, Instituto Nacional de Pesquisas Espaciais, São José dos Campos, Brazil
}

(Manuscript received 12 February 2007, in final form 20 September 2007)

\begin{abstract}
Large precipitation deficits observed during the 2001 austral summer over the southeast region of Brazil contributed to the worsening of the energy crisis that was occurring in the country, with unprecedented social and economic consequences. Reliable information on the beginning of the rainy season was essential for the Brazilian government to manage the energy crisis. The purpose of this study is to determine the rainy season in this region and to point out the risk of using outgoing longwave radiation (OLR) data to estimate the beginning of it. The results show that when OLR data are used the beginning and the end dates of the rainy season are wrongly anticipated and delayed, respectively. The present study aims to provide useful information for the management of the impact of adverse climate conditions such as the one in 2001 by basing the analysis on rainfall data instead of on OLR.
\end{abstract}

\section{Introduction}

The southeast region of Brazil (SEB) is the most populous and plays an important role in the economy of the country, being characterized by high industrial activity, agricultural productivity, and hydroelectric generation. Although Ramage (1971) did not consider South America (SA) as having a true monsoon regime, some studies revealed that a large part of subtropical SA experiences typical monsoon circulation (Zhou and Lau 1998; Gan et al. 2004). Particularly, SEB shows characteristics of a monsoon system, where the rainy season is the austral summer and the dry season is the austral winter.

During the 2001 austral summer the total rainfall was much lower than the normal values in southeastern,

Corresponding author address: S. Franchito, Centro de Previsão de Tempo e Estudos Climáticos, Instituto Nacional de Pesquisas Espaciais (INPE), CP 515, São José dos Campos, SP 12245-970, Brazil.

E-mail: fran@cptec.inpe.br northeastern, and central Brazil. Large precipitation deficits observed over these regions contributed to the worsening of the energy crisis that was occurring in the country. To control the crisis, the Brazilian government imposed rationing on the consumption of power in the beginning of the dry season (June 2001), which continued until March 2002. This led to an approximately $24 \%$ reduction in Brazilian consumption of energy, affecting even other regions where there was no rationing (Bardelin 2004). This energy crisis provoked significant social and economic consequences.

To help the Brazilian government to manage the energy crisis, the Minister of Science and Technology created a working group at Center of Weather Prediction and Climate Studies (CPTEC) that was entrusted with the task of analyzing the situation of the water level in the power-plant reservoir and predicting the beginning of the rainy season. To this working group was given the responsibility of issuing bulletins in real time. Many efforts were made to provide accurate information on the beginning of rainy season, which was essential for the Brazilian government to manage the energy crisis. 
Several criteria were used to estimate the beginning of the rainy season. Some studies used satellite-based outgoing longwave radiation (OLR) data to infer the precipitation. Although most of the studies that have been based on OLR anomalies are on the subject of intraseasonal variability of precipitation in SA (Nogues-Paegle and Mo 1997; Paegle et al. 2000; Carvalho et al. 2004; Gonzalez et al. 2006; and many others), there are a few investigations using OLR to identify and predict the onset of the rainy season in SA, mainly the onset in the Amazon basin (Kousky 1988; Horel et al. 1989; Marengo et al. 2001b). Other criteria to determine the beginning of the rainy season are based on winds (Gan et al. 2004, 2006) and rainfall data from rain gauge stations (Rao and Hada 1990; Cavalcanti et al. 2001). For the particular case of the severe drought of 2001, Marengo et al. (2001a) used OLR data to suggest that the rainy season over the basins generating electric energy in SEB begins between the end of September and beginning of October. Cavalcanti et al. (2001), using daily data of precipitation, showed that there is large variability in the beginning of the rainy season in SEB. However, on average it begins between the end of October and the beginning of November. So the two methods used to determine the onset of the rainy season showed different results. Since OLR is a measure of high cloud, the criterion commonly used to determine the rainy season with OLR data-values of OLR lower than $240 \mathrm{~W} \mathrm{~m}^{2}$-indicates the presence of deep clouds that only indicate the probability of precipitation. However, nonprecipitating high clouds like cirrus also show OLR values lower than $240 \mathrm{~W} \mathrm{~m}^{-2}$, and consequently the method may lead to wrong estimations of rainfall. Thus, a method to determine the rainy season based on rain gauges seems to be a more reliable indicator of precipitation characteristics.

The purpose of the present study is to determine the beginning of the rainy season in SEB based on rainfall data and to point out the risk of using OLR data to estimate it. This study aims to provide information for the management of the impact of adverse climate conditions such as the severe drought of 2001, which is a long-range objective of CPTEC.

\section{Data and methodology}

Rainfall data of 189 rain gauge stations for the period 1981-96 were obtained from Agencia Nacional de Energia Eletrica (ANEEL) and Sistema Integrado de Gerenciamento de Recursos Hidricos do Estado de Sao Paulo (SIGRH). Figure 1 shows the location of these stations. OLR data for the same period were obtained from NCEP-NCAR reanalysis (Kalnay et al. 1996).

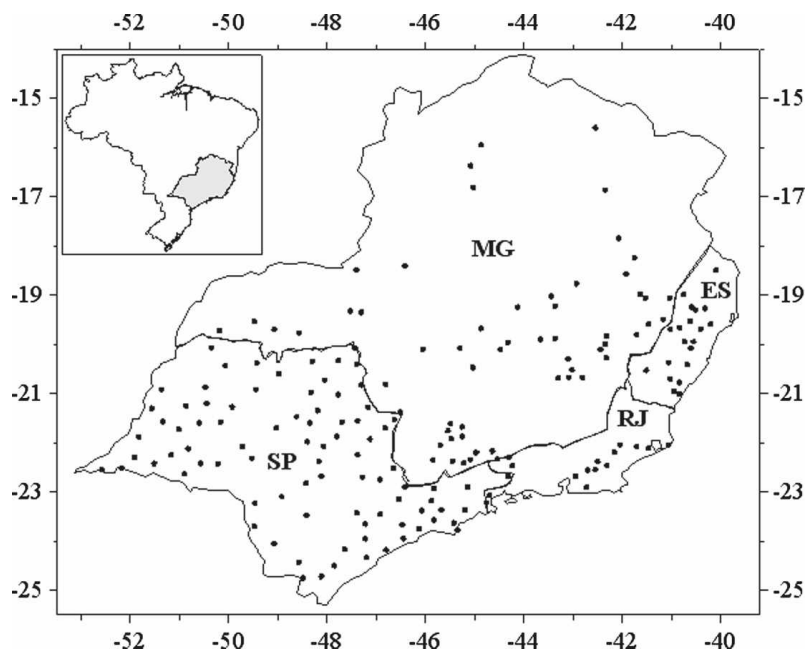

FIG. 1. Station location map. The schematic map of the entire country of Brazil including the location of the area of study is shown in the upper left of the figure. The letters SP, MG, RJ, and ES correspond respectively to the states of São Paulo, Minas Gerais, Rio de Janeiro, and Espirito Santo.

Pentad (5-day averaged) rainfall and OLR data were calculated.

To determine the rainy season using precipitation data for each rain gauge station $(i)$ for each pentad $(j)$ for each year $(k)$, the value of the accumulated precipitation at each 5 days $[p(i, j, k)]$ was compared with $\left[P_{5}(i)\right]$, which represents the 5-day accumulated precipitation if the annual rainfall was uniformly distributed during the whole year. Starting from 1 January, a ratio $r(i, j, k)=p(i, j, k) / P_{5}(i)$ was calculated, where $P_{5}(i)=$ $P(i) / 73$, and $P(i)$ is the mean annual rainfall. As a criterion for the beginning (end) of the rainy season, it was assumed that at least $50 \%$ of the values of $r(i, j, k)$ are higher (lower) than 1 (threshold value) at four consecutive pentads. Although this criterion might seem arbitrary, it was based on some important characteristics of the premonsoon and monsoon precipitation regimes. In the premonsoon period, rainfall may occur during some consecutive days (less than 10 days). These episodes of intermittent rainfall are not related to the beginning of the rainy season. The monsoon period (rainy season) is characterized by regular (not intermittent) rainfall, which occurs during at least 10 days continuously. However, after around 30 rainy days, periods with lack of precipitation may be related to the 30-60 day oscillation (Jones and Carvalho 2002). After these breaks, rainy days are again observed. Thus to characterize the rainy season we considered that the rainfall must occur continuously for a period of at least 10 days but less than 30 days. So we assumed that a criterion of the beginning of the rainy season is that at least one-half of 
the rain gauge stations $(50 \%)$ in the region show rainfall higher than the threshold value at four consecutive pentads (20 days).

To determine the rainy season using OLR data, the method used by Kousky (1988) was adopted. The criteria for the beginning (end) of rainy season were: (i) a pentad with OLR mean value lower (higher) than 240 $\mathrm{W} \mathrm{m} \mathrm{m}^{-2}$, (ii) at least 10 of the 12 earlier pentads with mean values of OLR higher (lower) than $240 \mathrm{~W} \mathrm{~m}^{-2}$, and (iii) at least 10 of the 12 subsequent pentads with mean values lower (higher) than $240 \mathrm{~W} \mathrm{~m}^{-2}$.

The number of the pentads and the respective calendar days relate as follows: pentad 1 corresponds to 1-5 January, pentad 2 to 6-10 January, ..., pentad 73 to 27-31 December.

\section{Results}

The prediction of the onset, intensity, and withdrawal of the monsoon constitutes a set of complex problems on which many researchers are working (see Sperber and Yasunari 2006). While the prediction of the arrival of the monsoon is a long-range goal, the present study has a more modest and reasonable goal of determining when the monsoon arrives, that is, to nowcast rather than to forecast. So we use two different methods to determine the onset of the monsoon and then compare the results. To evaluate which of the two methods better represents the onset and end dates of the rainy season, we must first identify these dates. In this paper we use the definition of the rainy season given by Gan et al. (2006). They determined the rainy season by considering that the onset (end) is defined when the precipitation is more (less) than $4 \mathrm{~mm} \mathrm{day}^{-1}$ for at least six of the subsequent eight pentads. Gan et al. (2006) used this definition to analyze the interannual variability of the rainy season associated with the monsoon over SA for an 18-yr period of precipitation time series (1979/ 80-1996/97). Their results indicated that the earliest and latest onset dates occurred in 13-17 September and 12-16 November, respectively. The mean onset and the standard deviation for the onset were 13-17 October and 15 days, respectively (see the two first columns of their Table 1).

First, the results using precipitation data from ANEEL and SIGRH are presented. As seen in Fig. 2a, the SEB shows distinct rainy and dry seasons. Starting from pentad 53 (18-22 September) the rainfall begins to increase. The change from the dry to the wet season occurs during pentad 58 (13-17 October). According to the criteria described in section 2 , the beginning of the rainy season occurs during pentad 59 (18-22 October) and the end during pentad 18 (27-31 March). The (a)

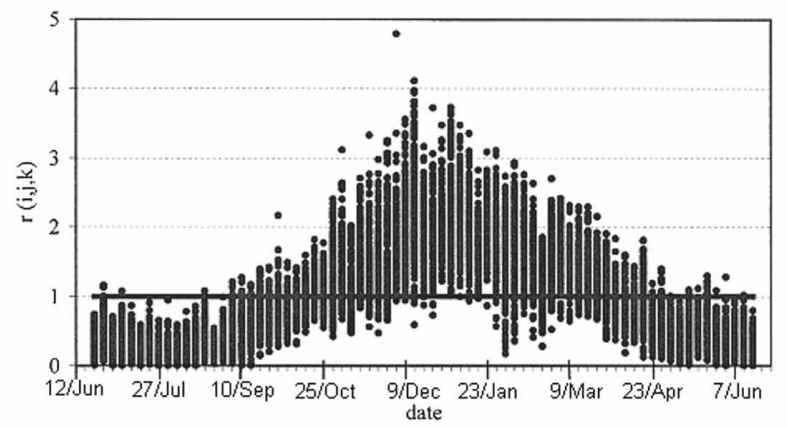

(b)

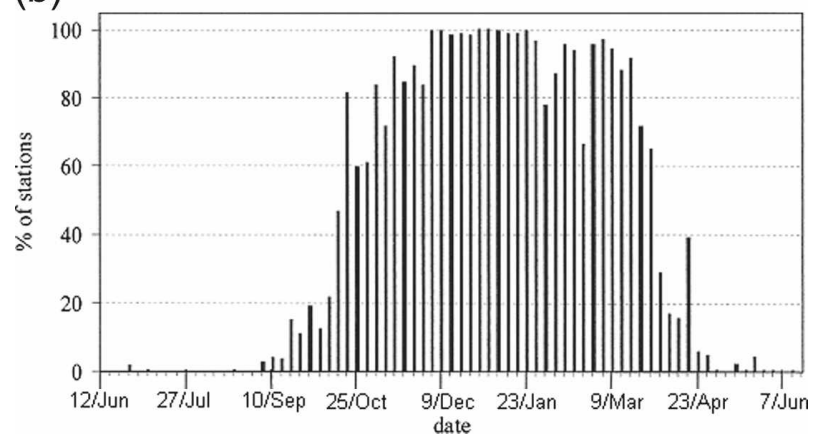

FIG. 2. (a) Values of $r(i, j, k)$ at each pentad, and (b) the percentage of meteorological stations with $r(i, j, k) \geq 1$ at each pentad. The dates correspond to the center of the pentads.

change from the wet to the dry season occurs around midautumn (pentad 19, 1-5 April). The period with highest number of meteorological stations with $r \geq 1$ occurs from the beginning of December (pentad 68, 2-6 December) to the end of January (pentad 5, 21-25 January; Fig. 2b). During the rainy season, the percentage of meteorological stations with $r \geq 1$ is higher than $50 \%$ in all of the pentads.

The results shown above indicate that the onset date of the rainy season obtained using the method based on rainfall is in agreement with the mean onset date and the variability of the onset dates for the monsoon in SA obtained by Gan et al. (2006). However, the end of the rainy season occurs 3 pentads ( 15 days) earlier than the mean demise date given in that study.

Figure 3 shows the distribution of OLR for the beginning and end of the rainy season in SEB. By midSeptember (pentad 52, 13-17 September), a deep convection band, which develops over Amazonia (Fig. 3a), advances southeastward, arriving in SEB by the end of September and beginning of October (pentad 55, 28 September-2 October; Fig. 3b). By mid-October (pentad 59, 18-22 October), a large cloudiness band with OLR values of $240 \mathrm{~W} \mathrm{~m}^{-2}$ is found over the entire SEB (Fig. 3c). By mid-April (pentad 21, 11-15 April) the cloudiness band starts to move toward the equator, and 
a)

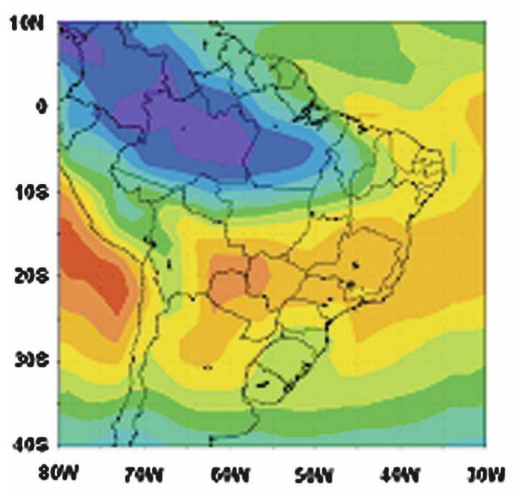

b)

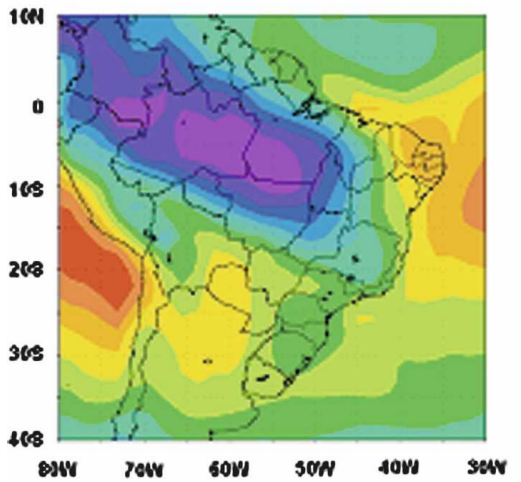

c)

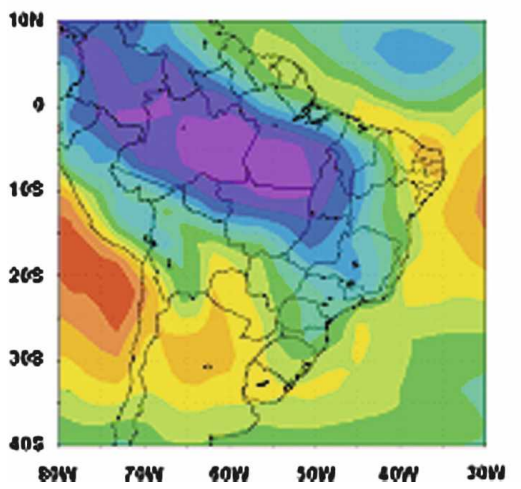

d)

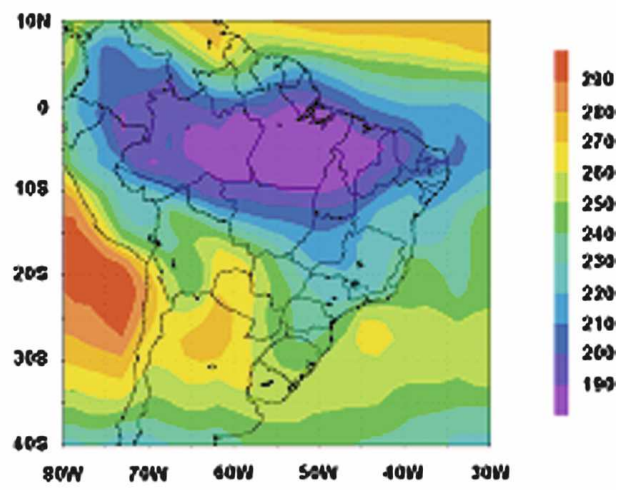

e)

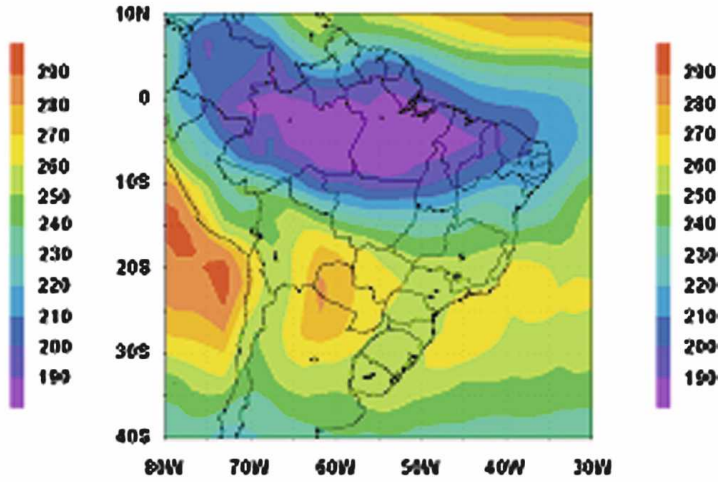

f)

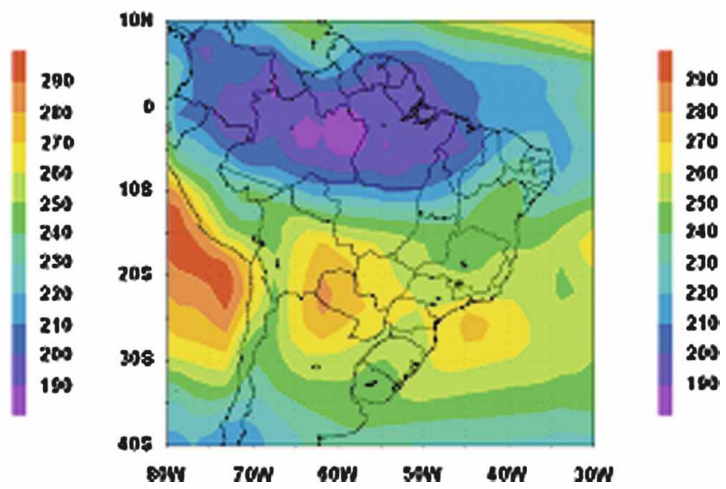

FIG. 3. Distribution of OLR values for: (a) pentad 52 (13-17 Sep), (b) pentad 55 (28 Sep-2 Oct, the beginning of the rainy season), (c) pentad 59 (18-22 Oct), (d) pentad 21 (11-15 Apr), (e) pentad 25 (1-5 May, the end of the rainy season), and (f) pentad 29 (21-25 May).

in the beginning of May (pentad 25, 1-5 May) the end of the rainy season in SEB occurs (Figs. 3d-f). These results are in general agreement with earlier studies using OLR data, such as Kousky (1988) and Marengo et al. (2001a), who found that the beginning of the rainy season occurred in the beginning of October and between the end of September and beginning of October, respectively.
The results presented above show that when OLR data are used the beginning (end) of the rainy season occurs four (seven) pentads earlier (later) than when rainfall data are used. The lag is larger for the end of rainy season. This may be due to the movement of deep convection toward the equator that is slower than its progress southeastward (Kousky 1988; Marengo et al. 2001b). Gan et al. (2004) suggest that the slower move- 
ment of deep convection equatorward is perhaps due to the storage of soil moisture during the rainy season. In any case, results of the present study show that there is a substantial difference in the determination of the rainy season depending on whether OLR or rainfall data are used. This discrepancy must be taken into account whenever an accurate determination of rainy season is crucial to establish strategies to deal with adverse climate changes such as the 2001 severe drought.

The discussion above considered the mean start and end of the rainy season when precipitation and OLR data are used. The same criteria (section 2) were applied to years of El Niño and La Niña events. During the period 1981-96, eight El Niño and four La Niña episodes occurred (additional information is available online at http://www.nws.noaa.gov). The El Niño and La Niña episodes and the pentad numbers corresponding to the beginning and end of the rainy season are given in Fig. 4. During El Niño events, the maximum delay of the beginning of the rainy season (pentad 69, 7-11 December) occurred in the 1991/92 and 1993/94 episodes, while in the 1982/83 episode the rainy season extended up to the end of April (pentad 23, 21-25 April). The shortest (17 pentads) and longest (40 pentads) rainy seasons occurred respectively in the 1991/92 and 1982/83 episodes. In the case of the La Niña events, the earlier end of the rainy season occurred in the 1983/ 1984 episode (pentad 6, 26-30 January).

When the determination of the beginning, end, and duration of the rainy season using OLR data is compared with the values obtained using precipitation data, large differences can be noted, as seen in Fig. 4. For example, in the longest rainy season observed during El Niño events, which occurred in 1982/83, the OLR method delays the end of the rainy season by 11 pentads. This wrongly overestimates by 13 pentads the duration of the rainy season. The beginning and the end of the shortest rainy season observed in the 1991/92 El Niño event were respectively anticipated and delayed by 16 pentads, thereby causing an erroneous increase of 32 pentads in the duration of the rainy season with the use of OLR data. During years of La Niña events, large differences between the two methods are also seen. In particular, in the 1983/1984 episode there was an erroneous delay of the end of the rainy season (pentad 29, 21-25 May) with OLR data when compared with the result when precipitation data were used (pentad 6, 2529 January). This discrepancy caused an apparent increase of 26 pentads in the duration of the rainy season. One should, however, be careful in analyzing the results of the differences between El Niño and La Niña events because of the fact that the number of events is not large in the time series used in the present study. The

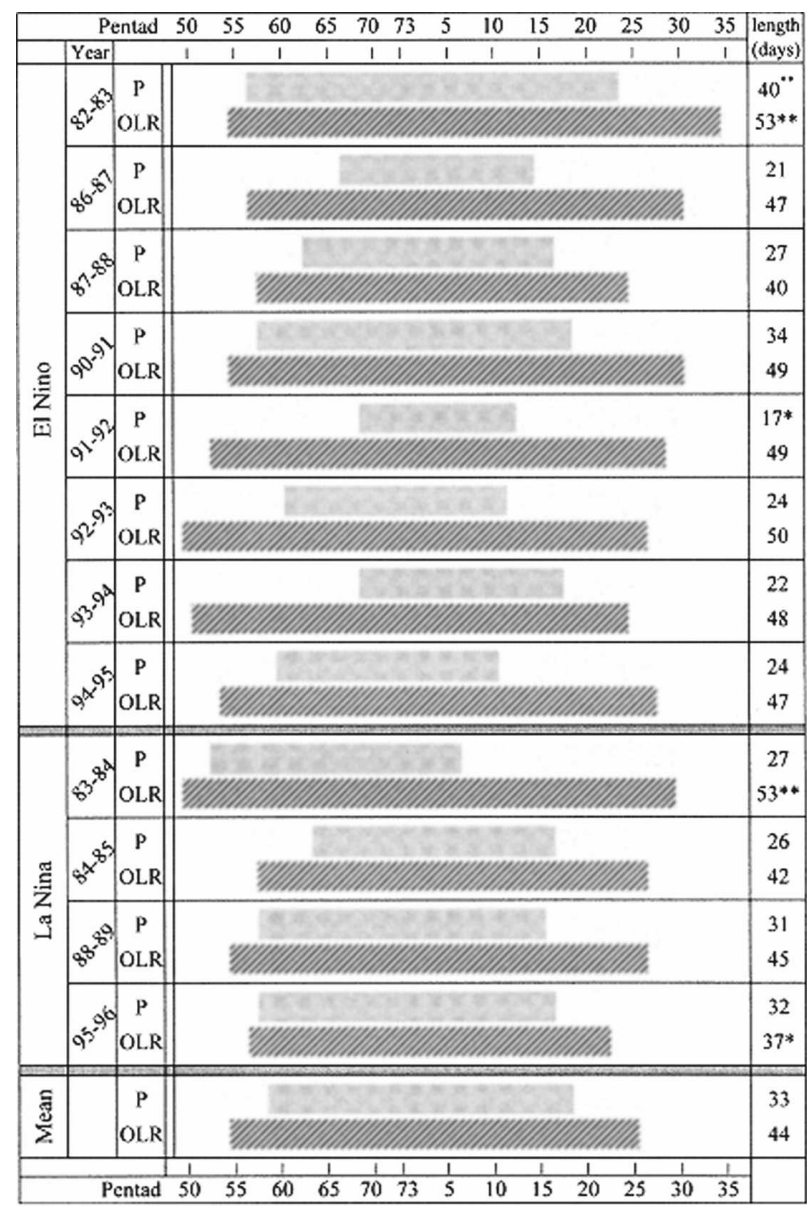

FIG. 4. Beginning, ending, and duration of rainy season during El Niño and La Niña events using precipitation $(P)$ and OLR data. Also shown are the mean climatological data (Mean). An asterisk indicates the shortest rainy season and the earlier beginning or end of rainy season; a double asterisk corresponds to the longest rainy season and the maximum delay in the beginning or end of rainy season.

conclusions should be reconsidered with further studies using a longer time series.

The results of the present work show that there is an overestimation of the rainy season using OLR data. The anticipation of the onset of rainy season using OLR data is in agreement with the results of other studies on the energy crisis in SEB (see Marengo et al. 2001a and Cavalcanti et al. 2001). We tested the same criteria based on rainfall (as described in section 2) for the meteorological stations located in the region of the basins responsible for the generation of electric energy in SEB and found that the beginning of the rainy season in SEB occurs at the end of November. The definition we used to determine the onset of the rainy season is a rigorous criterion in which the rainfall amount was enough for raising the low water levels in the reservoirs 
during adverse climate conditions such as the drought of 2001. Another test of the method based on rainfall data was made, this time considering all the available meteorological stations of São Paulo State (SP in Fig. 1). Based on the same considerations about the premonsoon and monsoon precipitation regimes mentioned in section 2, it was assumed as a criterion for the beginning of the rainy season that $r(i, j, k)$ was higher than 1 for at least three consecutive pentads or for two pentads followed by three pentads among four consecutive pentads. This criterion allowed an earlier onset of the rainy season when compared with that assumed in section 2, namely, $r(i, j, k)$ higher than 1 for four consecutive pentads. This new definition is sensitive to the necessities of many sectors of society, such as agriculture, human activities, and even the electric sector (in situations different from that in the severe drought of 2001 , when a heavy precipitation in the rainy season was needed to raise the low levels of water in the reservoirs). Despite this relaxation of the criterion, the onset of the rainy season still occurred between the end of October and beginning of November. Thus, even when the onset of the rainy season is defined less stringently, the onset as measured by rainfall data occurs later than it does when measured by OLR data.

The overestimation of the rainy season using OLR data may be attributed to fact that OLR is a measure of high cloud, but not necessarily of rainfall. The criterion described in section 2-values of OLR lower than 240 $\mathrm{W} \mathrm{m}{ }^{-2}$-indicates the presence of deep clouds that show only the probability of precipitation. Since nonprecipitating high clouds like cirrus also show OLR values lower than $240 \mathrm{~W} \mathrm{~m}^{-2}$, the method may overestimate the precipitation.

Although in the present study the validity of the rain gauge network data for estimation of precipitation is taken as granted, the method based on pentad rainfall data, described in section 2 , contains some limitations. Since the method is based on precipitation time series data, the estimation of the rainy season assumes that the rainfall behavior is similar to that of the past. Despite this limitation, the onset date of the rainy season obtained using this method is in agreement with the mean onset date and the variability of the onset dates for the monsoon in SA (Gan et al. 2006). Another method to determine the onset of the rainy season, which uses climate model's predictions, is based on winds. Since the skill of climatic models to predict the wind components is better than to predict precipitation, monsoon indices based on wind changes may be used to estimate the rainy season in the future. This method has been applied with some success to the west-central region of Brazil (Gan et al. 2004, 2006). However, there is a need for similar tests for the various regions of the country.

\section{Conclusions}

In this study, the rainy season in SEB was determined and the risk of using OLR data for this purpose was demonstrated. In addition, the changes in the beginning and end of the rainy season during El Niño-La Niña events as derived from OLR data were also examined. The study aimed to provide information for the management of the impact of adverse climatic conditions such as the severe drought in 2001. Pentad rainfall data from 189 rain gauge stations and OLR data from NCEP-NCAR reanalysis were used. The results showed that when precipitation data were used, the beginning and the end of the rainy season in SEB occurred respectively during pentad 59 (18-22 October) and pentad 18 (27-31 March). When OLR data were used, the beginning and the end of the rainy season were wrongly anticipated (four pentads earlier) and delayed (seven pentads later), respectively. When OLR data were used for the determination of the rainy season during El Niño and La Niña events, large differences in relation to the precipitation data were also noted. In the case of El Niño episodes, the beginning and the end of the rainy season were wrongly delayed and anticipated, respectively, up to 16 pentads while in the case of La Niña episodes, the duration of the rainy season was erroneously increased up to 26 pentads.

Thus, the wrong inference of the extent of rainy season with OLR leads to the conclusion that these data should be used carefully, especially in the case of adverse climatic conditions such as the severe drought of 2001, when accurate information about the beginning of the rainy season was essential for the Brazilian government to manage the energy crisis. Since the date of the onset of the rainy season obtained with precipitation data showed a good agreement with that obtained for the monsoon in South America, the criterion used here may be useful to determine the rainy season in SEB. The present study has attempted to provide meaningful and reliable information for decision makers.

Note that in regions where surface rain gauge stations are not available, the only available precipitation data may be those inferred from satellite data (by OLR and other means). However, in view of our results, great care should be exercised in inferring quantitative rainfall.

Acknowledgments. Thanks are given to Dr. Carlos A. Nobre for the efficient organization of the energy crisis 
group at CPTEC. Thanks are also given to the anonymous reviewers for useful suggestions.

\section{REFERENCES}

Bardelin, C. E. A., 2004: The effects of rationing electric power in Brazil in 2001 and 2002 with emphasis on the electric energy consumption (in Portuguese). M.S. dissertation, Polytechnic School, University of São Paulo, 113 pp.

Carvalho, L. M. V., C. Jones, and B. Liebmann, 2004: The South Atlantic convergence zone: Intensity, form, persistence, and relationships with intraseasonal to interannual activity and extreme rainfall. J. Climate, 17, 88-108.

Cavalcanti, I. F. A., C. A. Souza, V. E. Kousky, and E. B. M. Barbosa, cited 2001: Precipitation anomalies in the southeast region of Brazil (in Portuguese). [Available online at http:// www.cptec.inpe.br/energia/saiba/portalpop2.shtml.]

Gan, M. A., V. E. Kousky, and C. F. Ropelewski, 2004: The South America monsoon circulation and its relationships to rainfall of over west-central Brazil. J. Climate, 17, 47-66.

- , V. B. Rao, and M. C. L. Moscati, 2006: South American monsoon indices. Atmos. Sci. Lett., 6, 219-223.

Gonzalez, P. L. M., C. S. Vera, and B. Liebmann, 2006: Characteristics of the intraseasonal variability of precipitation over eastern Argentina. Proc. Eighth Int. Conf. on Southern Hemisphere Meteorology and Oceanography (ICSHMO), Foz do Iguacu, Brazil, Instituto Nacional de Pesquisas Espaciais, 1063-1088.

Horel, J., A. Hahmann, and J. Geisler, 1989: An investigation of the annual cycle of convective activity over the tropical Americas. J. Climate, 2, 1388-1403.

Jones, C., and L. M. V. Carvalho, 2002: Active and break phases in the South American monsoon system. J. Climate, 15, 905 914.

Kalnay, E., and Coauthors, 1996: The NCEP/NCAR 40-Year Reanalysis Project. Bull. Amer. Meteor. Soc., 77, 437-471.

Kousky, V. E., 1988: Pentad outgoing longwave radiation climatology for the South American sector. Rev. Bras. Meteor., 3, 217-231.

Marengo, J. A., L. M. Alves, C. A. C. Castro, and D. Mendes, cited 2001a: Information on the beginning of the rainy season in the southeast, west-central and south of northeast regions, which are affected by the energy crisis (in Portuguese). [Available online at http://www.cptec.inpe.br/energia/saiba/ iniciochuvas.shtml.]

— , B. Liebmann, V. E. Kousky, N. Filizola, and I. Wainer, 2001b: Onset and end of the rainy season in the Brazilian Amazon Basin. J. Climate, 14, 833-852.

Nogues-Paegle, J., and K. C. Mo, 1997: Alternating wet and dry conditions over South America during summer. Mon. Wea. Rev., 125, 279-291.

— L. A. Byerle, and K. C. Mo, 2000: Intraseasonal modulation of South American summer precipitation. Mon. Wea. Rev., 128, 837-850.

Ramage, C. S., 1971: Monsoon Meteorology. Academic Press, 296 pp.

Rao, V. B., and K. Hada, 1990: Characteristics of rainfall over Brazil: Annual variations and connections with Southern Oscillation. Theor. Appl. Climatol., 42, 81-91.

Sperber, K. R., and T. Yasunari, 2006: Workshop on monsoon climate systems: Toward better prediction of the monsoon. Bull. Amer. Meteor. Soc., 87, 1399-1403.

Zhou, J., and K.-M. Lau, 1998: Does a monsoon climate exist over South America? J. Climate, 11, 1020-1040. 